\title{
Choice, Control and Computers: Empowering Wildlife in Human Care
}

\author{
Jon Coe ${ }^{1, *}$ and Julia Hoy ${ }^{2}$ (D) \\ 1 Jon Coe Design, Pty Ltd., Healesville 3777, Australia \\ 2 Hidden Vale Wildlife Centre, University of Queensland, Grandchester 4340, Australia; j.hoy@uq.edu.au \\ * Correspondence: jon@joncoedesign.com; Tel.: +61-04-6737-8420
}

Received: 17 September 2020; Accepted: 9 December 2020; Published: 14 December 2020

\begin{abstract}
The purpose of this perspective paper and technology overview is to encourage collaboration between designers and animal carers in zoological institutions, sanctuaries, research facilities, and in soft-release scenarios for the benefit of all stakeholders, including animals, carers, managers, researchers, and visitors. We discuss the evolution of animal-centered technology (ACT), including more recent animal-centered computing to increase animal wellbeing by providing increased opportunities for choice and control for animals to gain greater self-regulation and independence. We believe this will increase animal welfare and relative freedom, while potentially improving conservation outcomes. Concurrent with the benefits to the animals, this technology may benefit human carers by increasing workplace efficiency and improving research data collection using automated animal monitoring systems. These benefits are balanced against cultural resistance to change, the imposition of greater staff training, a potential reduction in valuable animal-carer interaction, and the financial costs for technology design, acquisition, obsolescence, and maintenance. Successful applications will be discussed to demonstrate how animal-centered technology has evolved and, in some cases, to suggest future opportunities. We suggest that creative uses of animal-centered technology, based upon solid animal welfare science, has the potential for greatly increasing managed animal welfare, eventually growing from individual animal enrichment features to facility-wide integrated animal movement systems and transitions to wildlife release and rewilding strategies.
\end{abstract}

Keywords: animal-centered technology (ACT); captive; choice; conservation; enrichment; exhibit; reintroduction; wildlife; zoo

\section{Introduction}

This perspective paper discusses a wide range of existing and proposed technologies for improving the welfare of wildlife managed in zoos, aquariums, sanctuaries, and research facilities, and is intended to encourage interdisciplinary collaboration among technology specialists and animal carers and managers. Our goal is the improvement of the wellbeing of animals in human care, whilst also benefiting a wide range of related stakeholders including caregivers, managers, and visitors. Our strategy is to present an overview of this subject whilst providing three case studies with more detail and suggesting references with still greater detail for those needing that specific level of information.

As Zoos Victoria CEO Jenny Gray states: "Zoos have a social, moral and economic interest in the welfare of their animals" [1]. We would add that these interests intensify as concerns over animal welfare by both caregivers and communities increases. But even without such incentives our experience is that most carers and designers are driven to continuously improve the welfare of the animals and other stakeholders we serve; we owe them no less.

Mellor et al., state: "Animal welfare includes physical, behavioral and psychological aspects usually rated as a gradient from poor to good or from surviving to coping to thriving as a means of promoting positive welfare 
states." [2] This includes subjective consideration of animal feelings [3]. For a more complete discussion see $[4,5]$.

Considering animals' lives in an integrated, holistic manner, the Five Domains Model [2] is gaining strong international support. In addition, Coe suggests animal welfare initiatives focus on increasing animals' choice, control, challenge, change and, ultimately, competence, the 5Cs, or "Five New Freedoms" [6]. Both approaches begin by asking "How can we help these animals to not only cope, but to thrive?" Thus, in the most progressive facilities, achieving optimal animal welfare receives the highest priority. Initial welfare assessments are made of all existing animals, facilities and programs and remedial actions prioritized.

"Environmental enrichment (EE) describes how the environments of captive animals may be changed for the benefit of the inhabitants" [7]. "Research on enrichment supports the supposition that an enriched environment does indeed contribute to a captive animal's well-being." [7]. Environmental enrichment items, methods, and settings can be thought of as tools, technologies, and practices for improving animal welfare beyond basic needs. It is important to consider that although the focus of environmental enrichment has been remedial items and actions to compensate for enclosure deficiencies, well-designed enclosures are themselves intended to be enriching, supplemented by evolving EE practices. In our opinion, the best environmental enrichment practices also benefit animal caregivers, as well as researchers, and zoo and aquarium visitors. All stakeholders should be considered when developing enrichment programs and animals especially should become active co-designers [8].

We use the term "animal-centered technology" (ACT) to include a wide range of technologies, some predating computers, and including the growing field of animal-centered computing (ACI).

\section{Evolution of Animal-Centered Technology in Zoos and Research Facilities}

Animal-centered technology and design in zoos and wild animal sanctuaries began long before the computer age. As early as 1925 Yerkes suggested chimpanzees in his research colony should have an occupation to occupy themselves, as they had in nature [9]. During 1970-1980, some zoo professionals became increasingly concerned with the welfare of the animals under their care. Many, inspired by the writings of innovative Swiss biologist Hediger [10], sought remedial strategies to improve existing facilities and management practice to reduce what were considered negative animal behaviors not found in nature. Early environmental enrichment (EE) practices were developed and evaluated by pioneers such as Markowitz [11], and Chamove [12]. Many pre-computer forms of environmental enrichment, including much of Markowitz's pioneering work, used clearly artificial mechanical devices as substitutes for natural opportunities to simulate or stimulate behavioral opportunities like those found in the wild. For example, mechanisms from a commercial car wash were used to allow elephants to give themselves showers at the Washington Park Zoo in Portland in 1980 [13]. An elephant-activated shower at Columbus Zoo (Figure 1) as suggested by Coe in 1991 was shown to be used by elephants throughout the night to moisten dry hay before consuming it.

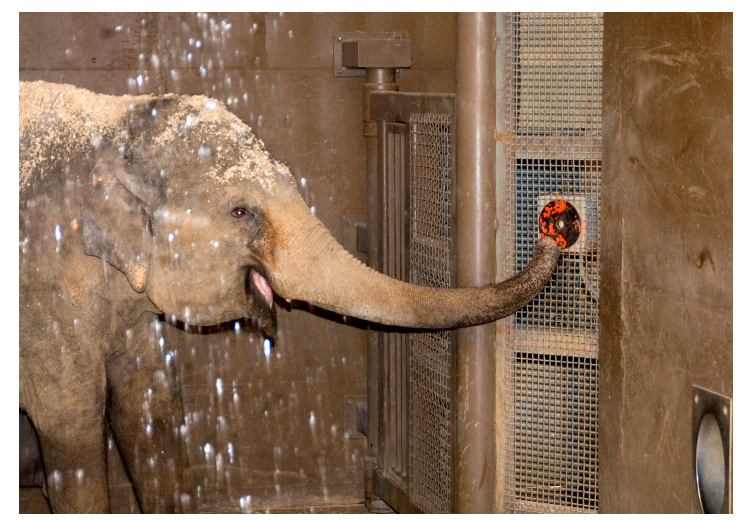

Figure 1. Elephant-activated shower at Columbus Zoo (Photo: H. Peachy). 
Many creative animal carers with low budgets began giving animals generally moveable objects such as homemade puzzles or large balls or tyres. A wide range of such ideas, as well as increasingly science-based design and evaluation processes, were shared through publications such as Shape of Enrichment [14] founded in 1991 and now providing international EE training programs. Another EE landmark was the 1993 establishment of the biannual International Conference on Environmental Enrichment by Shepherdson and Mellen, who, with Hutchins, also edited the important text "Second Nature: Environmental Enrichment for Captive Animals" [15]. Young's important 2003 book, "Environmental Enrichment for Captive Animals" [16] balanced EE methodology with practical "how-to" information. Coe also supported the use of changeable naturalistic enrichment features [17].

\subsection{Enriching Landscapes; Early Development of Animal-Centered Soft Technology in Zoos}

One of the authors (Coe) [18], David Hancocks [19] and their colleagues actively participated in the transformation of zoos from the medically and behaviorally sterile cells or concrete grottos of the 1950s-1960s to highly naturalistic immersive habitat simulations in the mid 1970's. This startling contrast is illustrated in Figure 2.
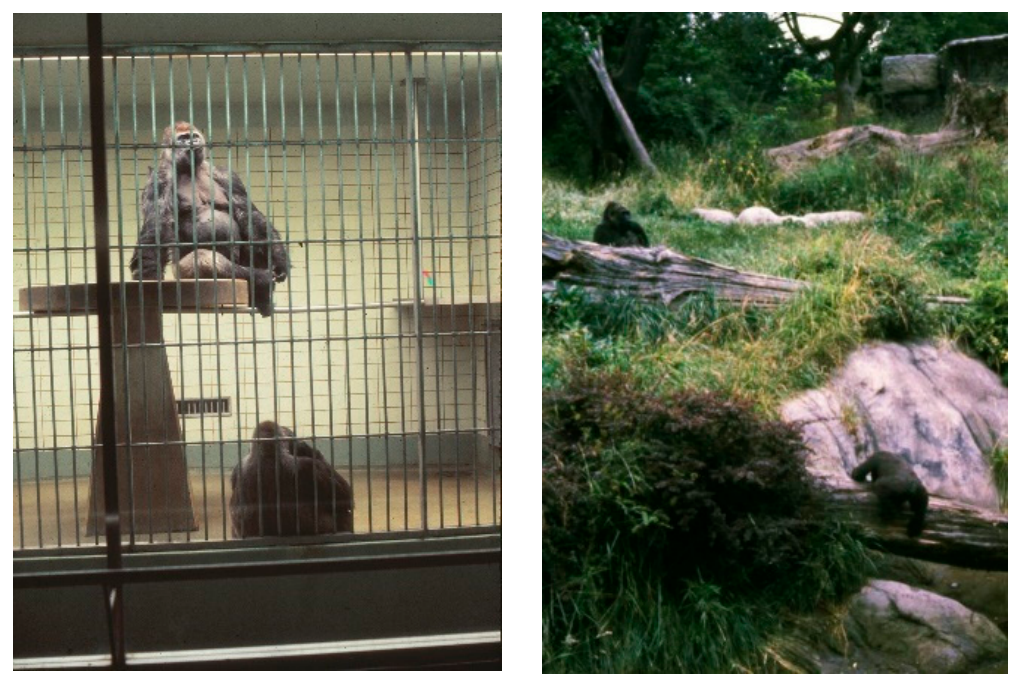

Figure 2. (Left) sterile zoo gorilla display and (Right) landscape immersion gorilla display at Woodland Park Zoo with many naturalistic enrichment features. Both were photographed in 1978 (Photos: J. Coe).

Highly naturalistic indoor exhibits include the Amazonia exhibit at the Smithsonian National Zoological Park developed by visionary director Michael Robinson in 1992 [20] and the Zoo Zurich Masoala Madagascar exhibit developed by Alex Rübel and opened in 2003 [21].

Coe and others continued to design many zoo exhibits using animal-centered technology in the form of naturalistic features such as artificial geology shaped to optimize solar azimuth angles to provide lions with access to sun in winter and shade in summer. Hidden enrichment technology included electrically heated artificial rock for animals to lie on, mechanically cooled rocks to shelter under, maintenance-free epoxy and steel artificial branches that swayed naturally when used by primates and intended to increase balance and muscle control (Figure 3), and pools with interactive underwater jets. In general, visitors responded positively to highly naturalistic and immersive animal display areas with unobtrusive animal enrichment features [22-24]. 

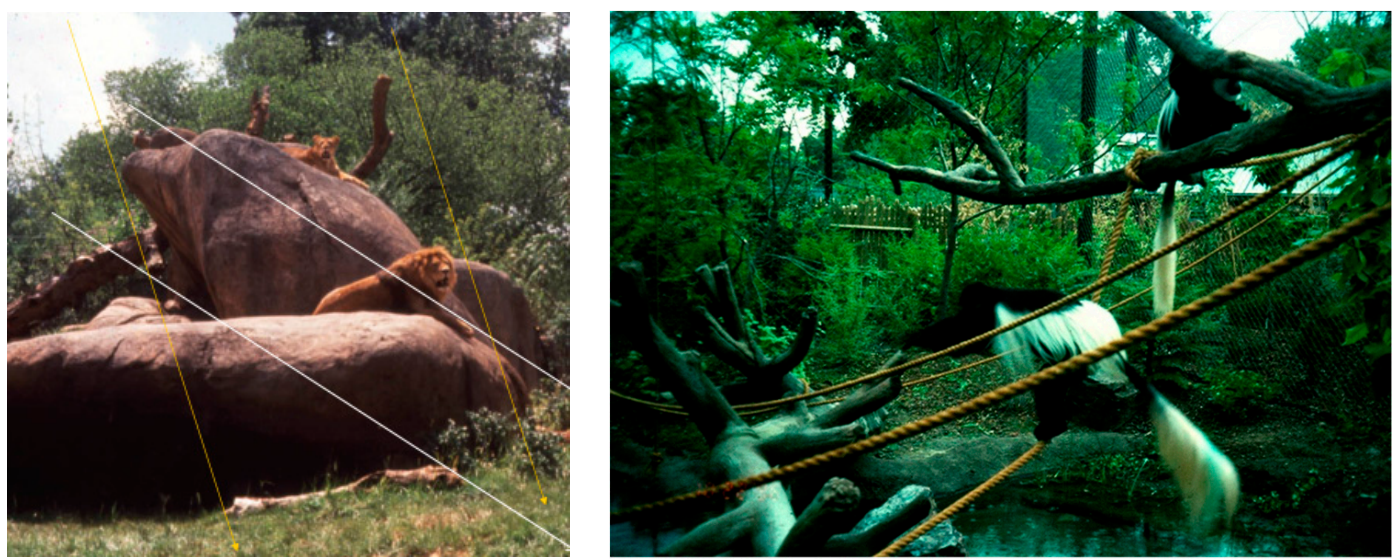

Figure 3. (Left) artificial geology designed to optimize solar azimuth for the lions' comfort at Zoo Atlanta. (Right) artificial branch designed to sway naturally at the Denver Zoo (Photos: J. Coe).

\subsection{Enriching Architecture}

Zoo designers and clients of early enriching exhibit landscapes also developed enriching indoor animal areas, where animals may spend up to sixteen hours of each day and much longer when species are not adapted to local conditions. While enriching landscapes are composed of combinations of "soft" and "hard" technologies [25], enriching architecture, is mostly limited to "hard" technology [5], but this can stimulate natural behaviours without looking natural. Martin and Shumaker refer to this as "functional naturalism" [26]. We extend this term to also describe synthetic features that provide equivalent functions to natural habitat features from what we presume to be the animal's perspective. Examples of animal-centered architectural technology (Figure 4) include the vertically oriented gorilla group room available to the apes 24/7 and combining "hard" and "soft" architecture with high windows providing distant views (Denver Zoo) and the Chimpanzee night building penthouse at Los Angeles Zoo, allowing the apes to sleep securely under the stars when they choose.
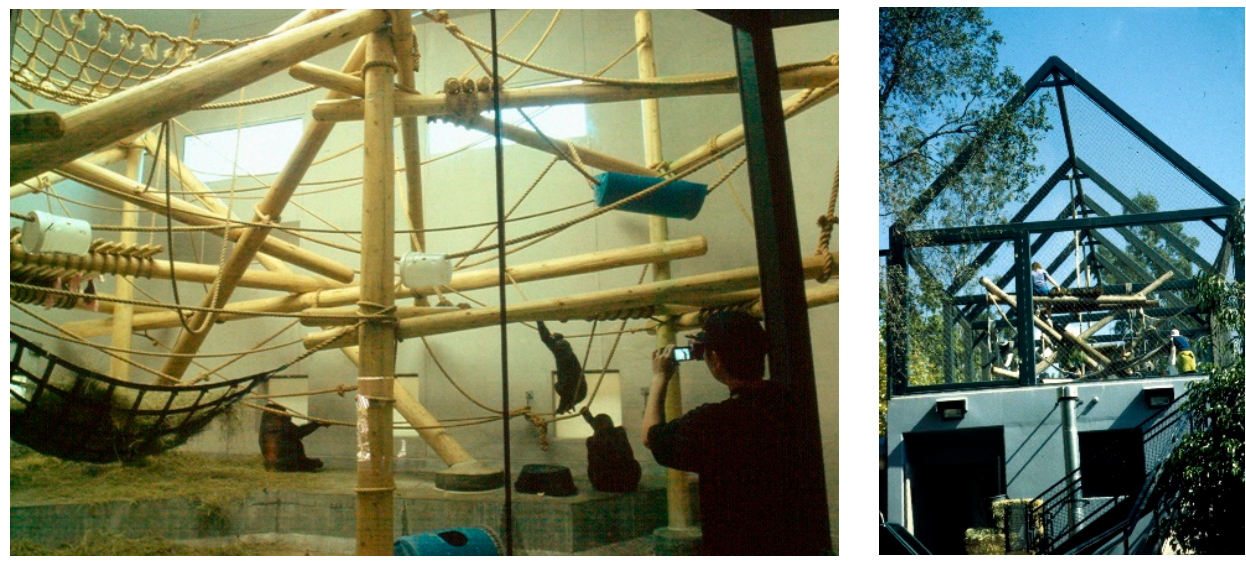

Figure 4. (Left) vertically oriented gorilla group room at Denver Zoo. (Right) Chimpanzee night building penthouse at Los Angeles Zoo (Photos: J. Coe).

Matsuzawa [27] and colleagues at the Primate Research Institute of Kyoto University developed three functionally naturalistic $15 \mathrm{~m}$ high chimpanzee towers in 1998 (Figure 5). These provide elevated shelter, broad vistas, and even sway like great trees when chimpanzees shake them during displays. 

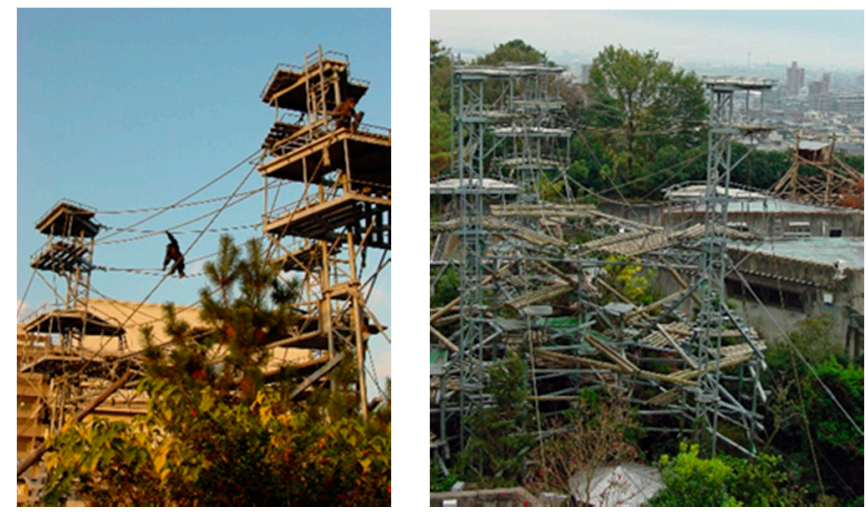

Figure 5. Two of the three functionally naturalistic chimpanzee towers developed by Tetsuro Matsuzawa (Photos: J. Coe).

\subsection{Enriching Changes in Animal Management}

In older animal management practice, carers used a combination of reward and coercion to elicit the animal behaviors they required. In the mid-1970s Pryor [28] developed a positive reinforcement training (PRT) method with dolphins in which coercion was used only in emergencies and the trainer no longer needed to be dominant. These techniques were expanded to land animal training and management by Pryor and others [29], revolutionizing the management of wildlife in human care. Coe introduced facility design changes to support these important management changes [30].

\subsection{Moving Outside the Box}

Wild animals of many species regularly move from place to place to meet their needs using trail networks connecting critical and favored resource locations, often sharing areas with other species. [10]. Why couldn't zoo animals explore adjacent display and off-display areas using a time-sharing system facilitated by animal-centered technology? Coe collaborated on the design of several such facilities at Zoo Atlanta in 1986, in Louisville Zoo in 1996, and Point Defiance Park Zoo and Aquarium in 2004. These management programs with raceway connections, called "animal rotation", "alternation" or "flex" exhibits [31] proved to be enriching to the animals using them [32], and popular with visitors [33]. Could this idea be extended? Coe envisioned the development of artificial animal trails interconnecting multiple areas within zoos and sanctuaries and giving animals much larger and more complex areas to explore [34]. The first extensive example of this type of animal-centered engineering technology was the elevated animal rotation raceways or "trails" developed at the Center for Great Apes in Wauchula, Florida (Figure 6). As suggested by Coe in 2000, these raceways presently extend to $2.5 \mathrm{~km}$ in length, connecting twelve night-houses and sixteen outdoor enclosures [35].
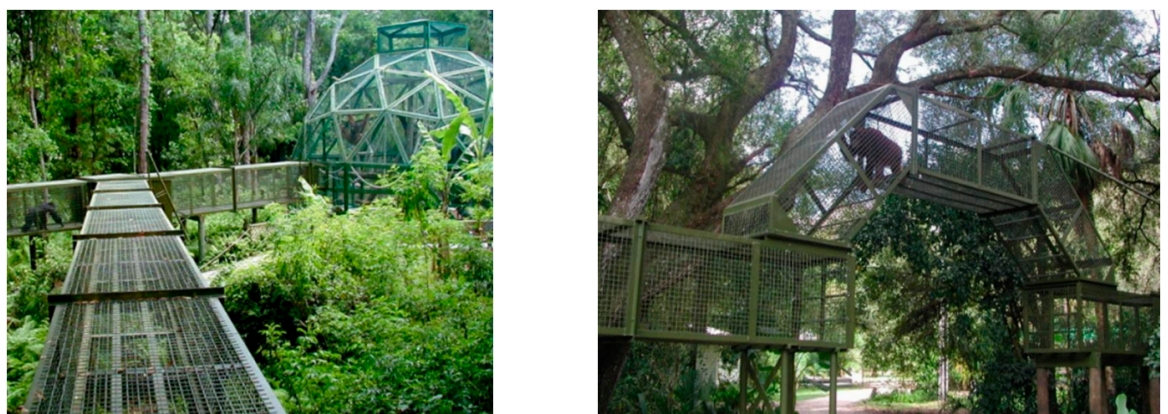

Figure 6. Elevated animal rotation raceways or "trails" developed at the Center for Great Apes in Wauchula, Florida (Photos: Center for Great Apes). 
Based upon the success of trail-ways at the Center for Great Apes, Philadelphia Zoo invited Coe and his colleagues to develop a zoo-wide trail system for their animals beginning in 2009. As of 2020, they have developed the $1 \mathrm{~km}$ round trip Treetop Trail used alternately by fifteen species of primate, the Great Ape Trail (380 m round trip), used by gorillas, orangutans, and gibbons, and the Big Cat Trail (160 m round trip) used alternately by six species of large cats. Zoo Guadalajara, Mexico, followed this direction in 2014 at Coe's suggestion, developing a 120 m elevated trail loop for smaller primates (Figure 7).
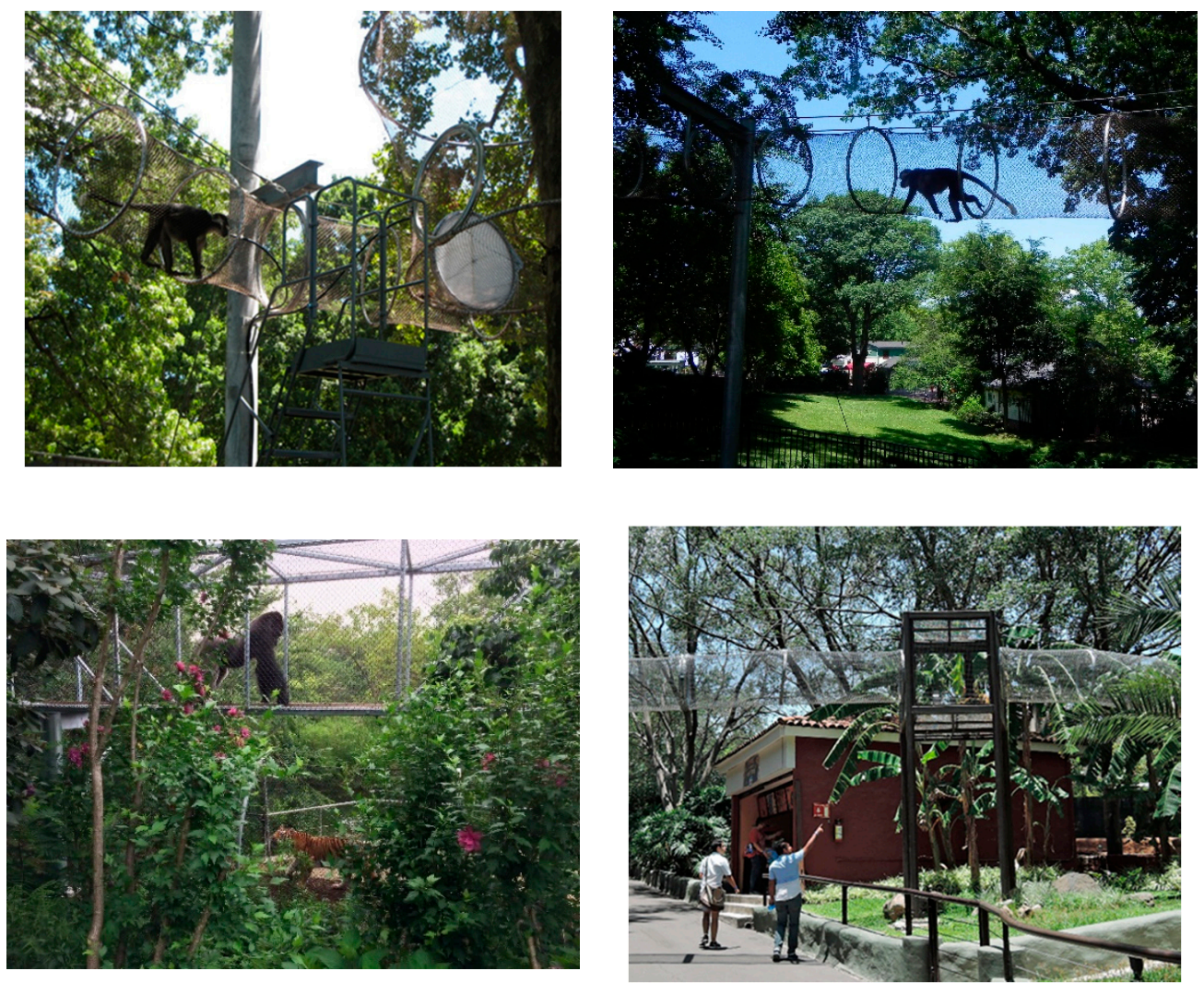

Figure 7. Upper photos of Tree Top Trail (Photos: J. Coe), lower left photo of Great Ape trail above Big Cat Trail (Photo: Philadelphia Zoological Society). Lower-right Sendarios, Zoo Guadalajara, Mexico (Photo: J. Coe).

\section{How Can Animal-Centered Computer Advances Provide Animals with Increased Choice, Control, and Relative Freedom?}

Free-ranging wild animals are entirely reliant on themselves and each other, developing what can be called physical and behavioral competence [6]. Are agency and freedom related? Freedom is relative. Hediger stated: " ... the free animal does not live in freedom; neither in space nor as regards its behavior towards other animals." ([10], p. 14). Wild freedom does not guarantee either comfort or long life compared to living in a good zoo or aquarium. What wild animals do have is increased agency and choice. Thus, it can be said the organism with the greatest degree of choice and control has the most relative freedom.

Despite the advances to built-in and changing environmental enrichment programs just summarized, animal care staff still provide for nearly all animal needs. This practice is not only very labor-intensive, but also leaves animals with little agency, sometimes leading to chronic stress, poor physical and mental fitness, in a welfare state of coping, but not thriving [2].

Rather than asking, "What can we do for these animals", we should ask," What can these animals do for themselves?" How can we facilitate greater independence? Animal-centered computing may help animals do more for themselves, for example by managing their ambient environments [36], 
feeding schedules, access to alternative spaces, and social opportunities at all hours, much like they could have in the wild [37] and thus encouraging natural activity periods [38]. As a result, it is believed animal stress levels are reduced and welfare limitations like "learned helplessness" would decline [16]. Properly managed to avoid animal dependency, such systems can even support animals during post-release stages of wildlife recovery and rewilding projects [39].

\subsection{Introductory References Covering a Wide Range of Animal-Centered Technology Applications}

This paper intends to provide a broad overview of animal-centered technologies. For more detailed reviews of this technology (including computer uses) in zoo visitor experience, education, research, and animal welfare through 2011, including a comparison of such uses in five North American zoos, see Clay et al. [36]. Whitham and Miller [40] provide an overview of monitoring systems such as accelerometers, GPS, bioacoustics, thermography, and radio frequency identification (RFID). As an excellent example of looking into a wide variety of computer-related uses in a single zoo, see Webber et al. [41].

\subsection{Animal Activated Touchscreen Computers}

Touchscreen computers in primate cognitive research are described by Perdue et al. [42]. Egelkamp and Ross [43] survey the history and wide international uses of such systems. They suggest that advantages of computer use include the ability to record data while researchers are not present, thus avoiding experimenter bias and improving efficiency. They note the addition of peripheral equipment such as radio frequency identification (RFID), motion sensors, facial recognition, and eye-tracking devices add to the range of research opportunities. Staff and animal training are important considerations in the use of touchscreen technology. The intended setting is also important, for example, in public areas where visitor education and possible interaction is intended, or in off-exhibit areas and isolated research settings. Once learned, touchscreen use appears to be enriching to the animal users, with ninety percent of apes and macaques tested at Lincoln Park Zoo voluntarily participating [43] and even sun bears actively participated at Zoo Atlanta [42].

Beginning in 2008, the orangutan exhibit at Zoo Atlanta allowed visitors to observe orangutans doing touchscreen computer tasks, including virtual painting [36]. The Think Tank exhibit and research site at the Smithsonian National Zoo, opened in 1994, was a pioneer in the uses of touchscreen computers in visitor education, and cognitive testing and symbolic language training for orangutans [44].

Orangutans at the Indianapolis Zoo Simon Skjodt International Orangutan Center " ... receive daily access ... to touch-panel and vending machine sessions at a publicly viewable laboratory space, opportunistic touch-panel task sessions using a portable cage-mesh mounted touch-panel device, and opportunities to gather food at a remotely controlled feeding apparatus located $27.5 \mathrm{~m}$ above the ground in their outdoor climbing area." [26]. This source contains many details and photos for those seeking more specific information on their applications.

Not all species have sensory or motor skills suited to touchscreen application and more extreme ambient environments may preclude their use. Hopefully, as the durability of this technology increases, opportunities for a much wider range of species will develop and perhaps underwater applications may become possible.

\subsection{Animal-Activated Virtual Reality (VR) Research}

Dolins et al. [45] showed bonobo, chimpanzee, and human subjects using a joystick to navigate within 3D desktop virtual reality (VR) environments on a large, fixed monitor. Whilst this study focused on comparative spatial cognition, the authors suggest chimpanzees, bonobos, and possibly other primates, may be able to use VR to entertain themselves, solve spatial and foraging problems relative to their species, and enjoy a sense of spatial expansion of their otherwise limited quarters. For example, perhaps they could explore virtual complex landscapes modeled on their natural habitats, with rolling topography, vegetation for concealment and foraging and other animal species to hunt or interact with 
in other ways based upon the animals' choice and control. Perhaps future VR applications could allow animals and visitors to interact in virtual environments in ways supporting both entertainment and conservation outcomes. Dolins also relates an example of a research lab bonobo which can operate a "robo-bonobo-bot" [45] well away from its enclosure, down office hallways, and even out-of-doors, allowing the ape to remotely explore actual landscapes and interact with real people in real-time.

\subsection{Motion Sensor Technology}

Clay et al., note: "In state-of-the-art facilities, control over elements such as room temperature, access to outdoor areas, access to social partners or to privacy, for example, permits animals to make choices about their physical and social environments." [36] (p. 492).

Maple and Perdue ([5], p. 147) agree, saying "... the more that animals can do for themselves the better." Over 25 years ago Coe [46] visualized uses for motion sensitive activators for chimpanzees and other laboratory animals, controlling indoor ambient conditions such as light levels and spectra, ventilation, temperature, and humidity in their individual areas simply by positioning themselves in the vicinity of motion sensors controlling these features. This could be a functionally naturalistic equivalent to wild animals meeting their ambient needs by moving through natural ambient gradients in their habitat. In both cases the animal maintains some agency in achieving its preferences. Underwater jets with variable water temperatures and velocities or air bubble curtains could be activated by aquarium animals and species such as platypus, otters, tapirs, tigers and bears by moving through motion sensor fields. However, to our knowledge such motion sensor activated features have never actually been developed, yet this opportunity remains open for experimentation. Motion sensors are used in parallel with RFID microchips to activate microchip feeders and doors as described later by Hoy.

\subsection{Computer-Controlled Feeding Systems}

Highly specialized feeding systems are increasingly used in precision livestock management [47]. One widely used commercial product, Feedpods [48], was adapted from the livestock industry for zoos. It uses a cloud-based management system for remote control with smartphones and has been installed in twenty countries. A 35\% increase in animal activity and foraging and 10\% reduction in stereotypical behaviour is claimed for this product [48]. As an example, Dublin Zoo uses the Feedpod system as part of their after-hours elephant feeding system to encourage movement, physical condition, and enrichment. When combined with daytime manual feeding strategies, the zoo found their elephants travel $9 \mathrm{~km}$ per day between food sources, a distance similar to that measured with wild elephants [49]. Some zoos have developed their own timed-release feeders for nocturnal animals active after normal staff hours, reporting increases of both frequency and diversity of species-typical behaviours as a result [50].

\subsection{Implantable Biosensors}

Present and next-generation miniature implantable biosensors " .. have great potential in the diagnosis, monitoring, management and treatment of a variety of disease conditions ", and " ... supporting new initiatives in livestock management" [51]. While such technology is presently used in biometric research, it appears to hold promise, along with related RFID systems, to measure body temperature and, in the future, other indicators of wellbeing, while animals engage in environmental enrichment and cognitive research programs.

\subsection{Radio Frequency Identification (RFID) Microchip Activated Technology in the Captive Setting}

We emphasize the utility of a commonly used implanted device, the RFID microchip. Most animals in human care have been implanted with RFID microchips for identification. Scanners identify specific animals, allowing only pre-selected individuals to activate devices such as microchip-controlled doors and feeders [52]. 
The Primate Research Institute of Kyoto University implanted RFID microchips in the wrists of chimpanzees, enabling a computer to record data from individual animals over multiple tasks, including work designed specifically for that animal, which can work when it pleases, alone or in its group. RFID " ... technological devices such as the microchips just described can enhance not only animal welfare, but also the quality and quantity of data collected." [36].

\subsection{RFID Tracking for Research}

Dallas Zoo has used RFID ankle bracelets (Figure 8) to track elephants, gathering round-the-clock information on herd social organization, exhibit utilization during environmental enrichment trials, movement speed, distance traveled, time and location of resting periods, and weight management [53]. This anklet features a break-away connection to prevent the elephant from becoming tangled.

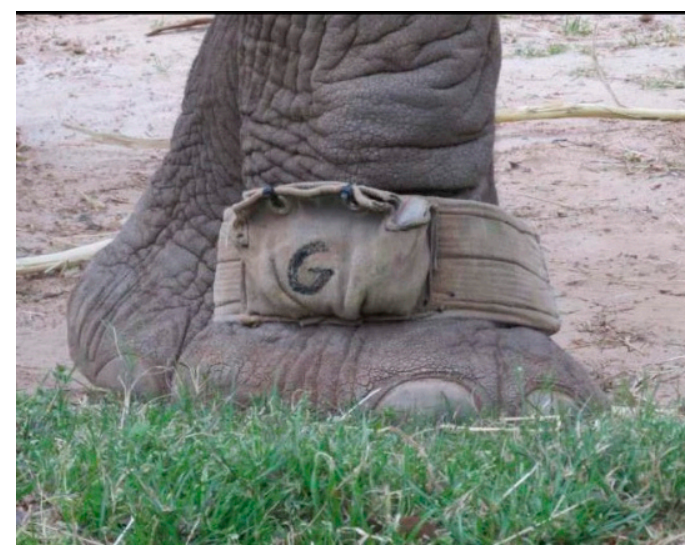

Figure 8. RFID tracking anklet developed by Dallas Zoo (Photo: Dallas Zoo Management Inc.).

\subsection{RFID Microchip Technology in Captive Wildlife Management. Brief Case Study A}

Using microchip technology as enrichment for research animals was first trialed by Hoy in 2007 with captive owl monkeys (Aotus spp.) using a prototype microchip-controlled feeder device [54] (Figure 9). Whilst successfully proving that this species can control access to elements of their environment using microchip devices, there were major limitations to available technology at that time, and the effectiveness of the device as a source of enrichment was inconclusive [54].

High cost was shown in an international zoo survey to be considered prohibitive to the widespread adoption of such microchip-activated equipment in captive wildlife facilities [52]. Further advances by others over a decade after the Hoy microchip feeder prototype resulted in the manufacture of commercially available microchip-controlled pet feeders and doors by Sure Petcare [55]. These off-the-shelf devices are relatively inexpensive, making them more suitable for use with managed wildlife.

The first reported use of one of these Sure Petcare microchip pet doors was with a captive-bred bridled nailtail wallaby (Onychogalea fraenata) trained to use such a door to access feed and refuge [56]. A wild-caught captive brush-tailed phascogale (Phascogale tapoatafa) was later trained to use both a Sure Petcare microchip door and feeder [57].

There are a range of potential benefits to the animals of adopting such technology, including an increase in the frequency and variety of enriching opportunities within the captive environment, which were applications considered most valuable by animal care staff globally [52]. Using ACI technology to reduce human contact with wildlife destined for release will become increasingly important into the future as these programs become more common, and additional remote management capabilities are developed. 


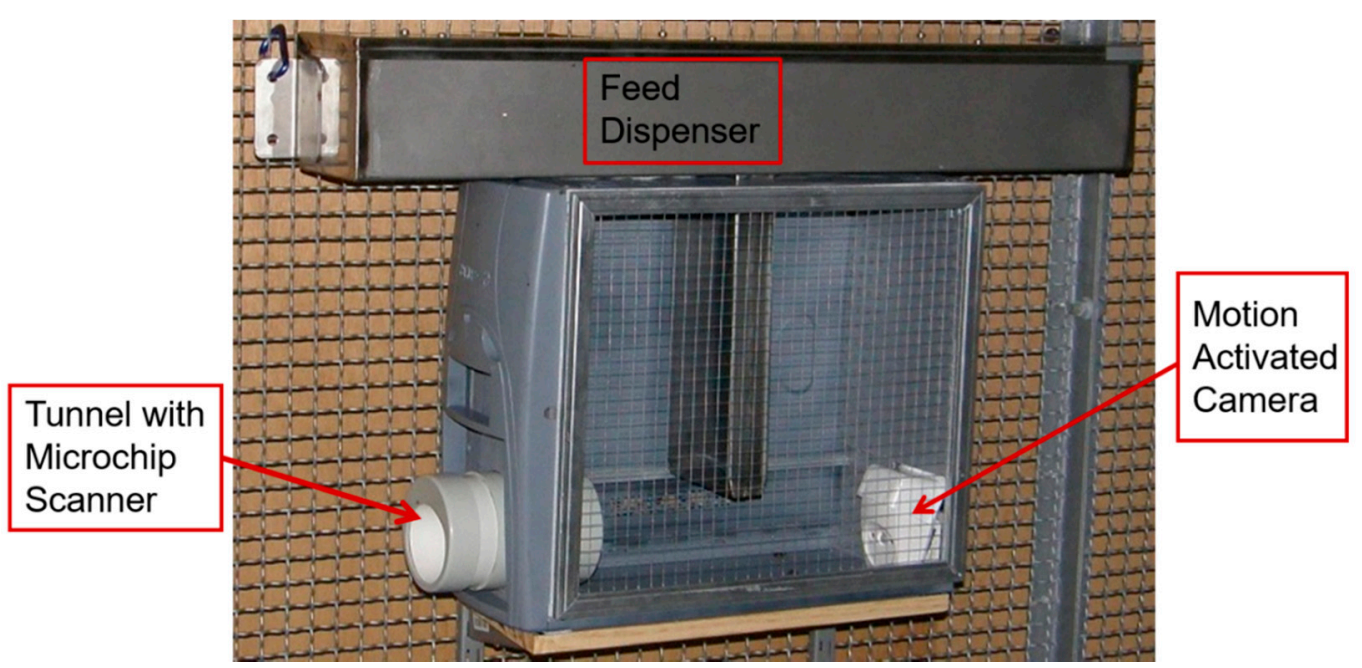

Figure 9. Prototype microchip feeder developed for use with captive owl monkeys in 2007 (Photo: J. Hoy).

\subsection{RFID Microchip Technology in Animal Reintroductions. Brief Case Study B}

Captive breeding of wildlife and subsequent reintroduction to the wild is becoming increasingly important [58]. One major challenge is the need to provide food and refuge from predators for released animals until they are able to meet their needs without assistance [39]. However, it is critical that supplementary support is not inadvertently provided to competitor or predator species. Historically this issue has not been well addressed, but now RFID microchip technology allows access to resources only on recognition of a microchip implanted under the skin of a particular individual. To test this theory, wild-born northern brown bandicoots (Isoodon macrourus) were trained to use commercially available microchip doors attached to a timber nest box in captivity (Figure 10) [39].
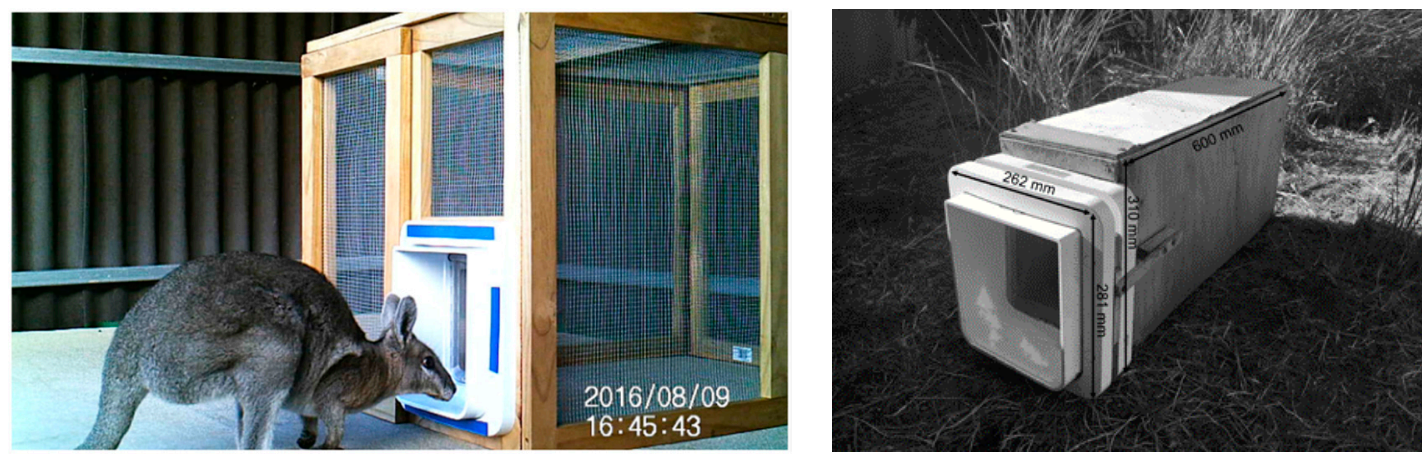

Figure 10. (Left) commercially available Sure Petcare RFID microchip controlled pet door adapted for use as a wildlife provisioning station and refuge with a bridled nailtail wallaby (Photo: S. Muns) [56]. (Right) Prototype microchip controlled nest box used with northern brown bandicoots (Photo: M. Edwards) [39, 59].

These bandicoots were then released back to the wild with the microchip nest boxes supplementing them with feed and shelter, while also allowing monitoring of their survival [59]. The bandicoots rarely used the doors upon release, but the technology showed great potential, and is likely to be more effective for other species that are hollow dependent [59]. Being able to use RFID controlled technology as well as other ACI advancements could create opportunities to improve the success of wildlife reintroductions and monitoring of threatened species in the wild when appropriate consideration is given to prevent potential issues such as learned dependence on the technology. 


\subsection{Animal-Activated Light Projection Games. Brief Case Study C}

During a Melbourne Zoo meeting on orangutan environmental enrichment in June 2014 Coe suggested installing an ape activated light organ projecting in both animal and adjacent public areas. It was thought this would entertain both apes and visitors while giving orangutans some choice and control over visitor behavior. Then in 2015, the UniMelb Social NUI Centre (funded by Microsoft Research and the Victorian State Government) approached Zoos Victoria, suggesting developing an animal interactive system using a Microsoft Kinect device. They explored a variety of options before deciding on interactive projections. The final system uses the input from the infra-red depth sensor and camera on a Microsoft Kinect device to detect touches on a projected screen, using a standard LCD projector (Figure 11). These touches then become inputs to games or applications running in the Unity game engine [60]. An evaluation by Webber et al. [8] found that animals using it showed more play behaviors and overall activity when an application was activated, but habituation lessened this effect over time. However, the evaluation form selected by the client required this enrichment system to be fixed throughout the evaluation period and in the end "... the quantitative data gathered did not contribute to understanding which aspects of the installation were of most value to the orangutans or support improvement." [8] (p. 1720). The principal author later suggested that an iterative rather than fixed evaluation process could have better allowed designers to home in on key features of the study of most interest to the participating orangutans [61].

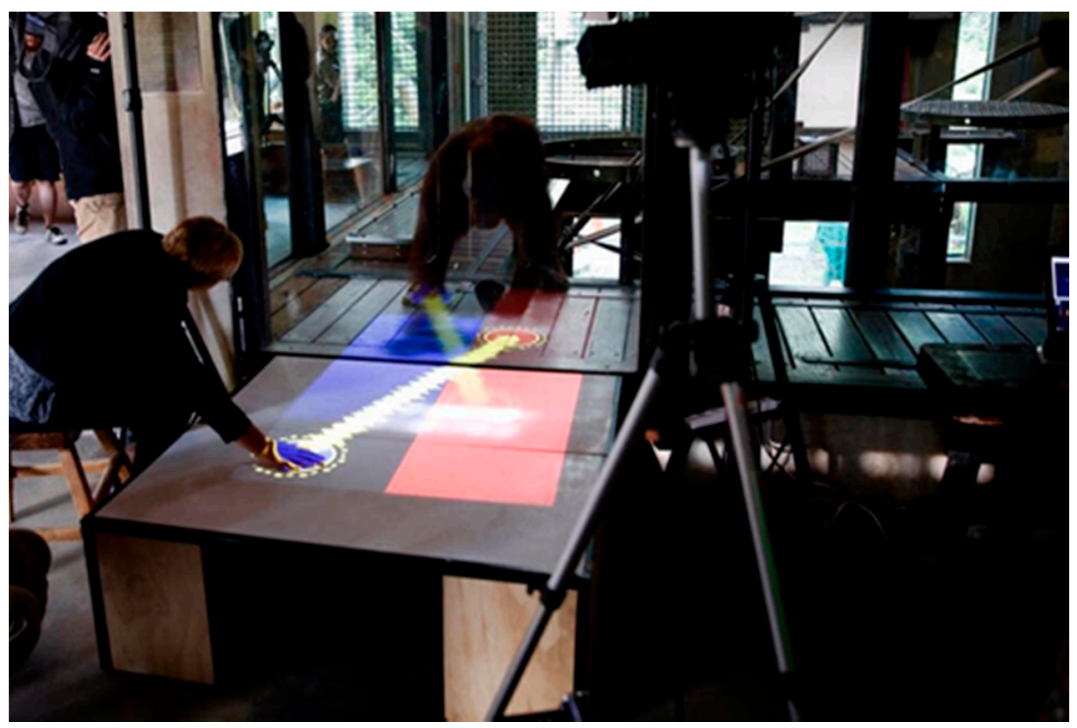

Figure 11. Prototype light game between orangutan and researcher at Melbourne Zoo (Photo: Zoos Victoria).

\section{Promising but Untested Opportunities}

What is our perspective on opportunities building upon the enriched landscapes, buildings, and animal-centered technology systems described earlier?

\subsection{Giving Animals More Control of Rotation Exhibits and Trails}

At present animal rotation and movement between areas, as described in Section 2.4 and Figures 6 and 7 , is managed by animal care staff. However, could RFID-controlled smart gates and smart feeders, as described previously, be animal controlled using ACT programs, giving animals more control over access while ensuring safety for animals and staff [34]? Could these also be programmed remotely by animal care staff, as Dublin Zoo has done with their elephant feeders [62]? What would such a system be like? For example, on a Monday the tiger may choose its desired trail route and destination. Then the leopard may be able to take any trail segment it wants except the one occupied by the tiger. 
The order can be changed through the week or selected randomly by the staff or a master animal movement control system. Could presently staff-operated gates like those in the animal trail system at Philadelphia Zoo (Figure 7) be animal-operated in the future?

\subsection{Master Animal Movement Control Systems}

Ultimately, as zoo animal trails become increasingly interconnected, perhaps a computer-based monitoring and recording system, like a mini-metro train control system, could be developed to ensure safe operation while recording animal movements. Present and next-generation implantable biosensors [51] could record body temperature and other biometrics each time a specific animal passes through a smart gate. This action could also prompt surveillance videos of the animal passing through and visitor and staff activity in the area. The resulting records of the animal's activities, exertions and time budgets would assist scientists in monitoring physical, behavioral, and psychological wellbeing. Visitor reactions, including hoped-for experiential enrichment associated with animal's movements, could also be assessed. Smart gates could also automatically update electronic public information and Wi-Fi systems to let visitors with smartphone apps know where specific animals are in the trail system.

\section{Concerns and Opportunities}

What problems should be considered in adapting computer technology in zoos, aquariums, and related settings? All animal-centered technology must of course be suited to both the needs and capabilities of the animal users, the context within which it is expected to operate and the theme or message it is intended to convey to stakeholders (see later discussion in Section 5.5 "message").

\subsection{Site and Service Considerations}

Both mechanical and electronic equipment must not only be durable enough for use by the intended species and weather-proof, but also may need to compensate for local unavailability of power or telecommunications services and protected against invasion by local rodents. It must be safely and conveniently accessible for needed service, ideally without the need to remove the animals from the area. Some fixtures such as solar panels and batteries, surveillance cameras, remote control systems, RFID and motion sensor systems may need only infrequent access and present an opportunity to reduce maintenance and support infrastructure. Direct contact animal-operated controllers such as joysticks and touchscreens should be located where trainers can conveniently work with the animals. Timers and other controllers requiring frequent change and automated feeders needing frequent provisioning require convenient access.

\subsection{Efficiency and Perceived Value}

In the 1990s, the expense, delays, and inconvenience caused by repair, scheduled service, and replacement of equipment, together with rapid obsolescence of computer-aided educational systems, give computer-based systems a bad name in the zoo industry. The most voiced concern seemed to be: "But is it worth the cost? Is there an easier way?" [63]. Today, animal care staff always have more to do than their allocated time allows [64]. To be accepted by them, technical apparatus must not only clearly benefit the animals, but must also save them time. Additional time for training to operate technical apparatus must be justified by real convenience later. Also, some excellent carers may not be proficient with novel gadgets, and overcoming natural resistance is essential to long-term success. Fortunately, advances in human-friendly systems now appear to have reduced staff opposition. Devices operated by familiar smartphone and tablet technology should be more widely accepted if design, installation, and operating costs are well justified by improvements in animal welfare, carer efficiency, and visitor approval. 


\subsection{Are Positive Personal Relationships between Caregivers and Animals Threatened by Increased Automation?}

Positive personal relationships between carers and animals are essential to good animal husbandry and are a major professional motivator for caregivers [65]. As animals gain greater choice, control, and self-sufficiency using ACT, this relationship may be eroded, perhaps resulting in less personal satisfaction for carers and increased wildness and willfulness of animals. This "wildness" is an essential characteristic for animals scheduled for future release and has benefits in terms of communicating valuable educational messages to visitors. However, increased management and research efficiency should be planned to increase and not diminish staff access to activities they find to be both enriching to themselves and the animals if carer support is to be maintained.

\subsection{Safety}

All apparatus must be safe for all users, human and animal, initially and in the long-term. While the Shape of Enrichment safety database [14] is a rich source of information on safety considerations for traditional enrichment features based upon animal taxa, type of enrichment, and type of hazard, we are unaware of published recommendations specifically for computer-based forms of enrichment. However, better zoo, aquarium, sanctuary, and lab animal facilities have well-defined safety protocols and awareness which should always be applied to design reviews.

\subsection{What's the Message?}

There is a long and contested debate between supporters of naturalistic versus functionally naturalistic enrichment feature over the impact on visitor education and experience of "unnatural" looking enrichment features in naturalistic animal display settings. For the purpose of this paper, we urge designers to be aware of the "message" implied to visitors experiencing their work [66]. Designers should collaborate with zoo or aquarium educators and find design solutions benefiting the animals, the institution's educational objectives, and other stakeholders on a case-by-case basis. However, when enrichment interventions are intended to support a high-tech educational message, such as in the National Zoo Think Tank or the Indianapolis Zoo Simon Skjodt International Orangutan Center, or are applied in non-public areas, the technical medium can become the desired message.

\section{Design Process for Developing ACT Technology}

Here follows a typical planning sequence; the process will vary with each client and project. For a detailed specific example see Webber et al. ([8], p. 1719) for an excellent study of interactive technology and human-animal interaction at Melbourne Zoo.

\subsection{Design Team}

Depending upon the overall project context, either in a public display or a non-public research and animal management area, the design team should include a diverse group of client staff, including decision-makers as well as hands-on operators, animal welfare and training specialists, educators, and evaluators, exhibit designers, including IT specialists, and the client animals.

\subsection{Pre-Occupancy Testing}

Ideally, the animals and staff for whom the enrichment features are being designed would be tested ahead of time to determine baseline behaviours which can later be compared to final post-occupancy testing to determine what benefits have been achieved.

\subsection{Co-Design with Animals}

Finding ways to include the animals as co-designers is a key discussion point. See Webber et al. ([8], p. 1715) for an example with orangutans and French et al. [67] with elephants for more detailed case-specific considerations. Both studies determined that prototyping and testing ideas directly with 
the animals on an iterative trial and error basis was the best way to determine the animal's level of interest, ability to use the feature, and the project's likely success. This requires flexible and timely methods of evaluation throughout the design process, and not simply post-occupancy evaluation upon final installation.

\subsection{Design Workshops}

The first meeting, often called the vision session, unusually includes the institution's senior staff as well as animal care workers to define their overall "vision" or aspiration for the project, including goals, objectives, and available resources. This is then developed by an interdisciplinary client group into a formal project brief containing all critical information needed by the ACT and other designs. This document must remain somewhat flexible to adapt to creative opportunities or changing conditions during the early design stages.

\subsection{Site Inspection and Appreciation of the Design Brief}

The second meeting begins with a site inspection for the design team (consultants and staff) lead by zoo staff with a briefing on both visitor experience and education expectations and animal care concerns, to fully understand both the project context and the nature of the animal clients, including their unique sensory preferences, motivations, and personalities, both as species and individuals. This meeting would include presentation and discussion of the client's draft project brief clearly identifying the need for the work (problem definition), project location and area, available funds, time, and other critical resources and constraints. Zoo staff may also point out enhanced enrichment examples from other locations illustrating their initial ideas, but these should not be fixed at this early stage nor simply copied without improvement. An interdisciplinary brainstorming session follows, identifying several prioritized options for further development. The meeting concludes with a clear understanding of the client's brief, project objectives and evaluation criteria, and progress expectation for the next design meeting.

\subsection{Preliminary Design}

The designers review the brief, do additional research, and develop promising directions which are then presented to the client team, including general costs, development time, and other requirements. After discussion and evaluation, the group selects the preferred design option for the iterative prototyping and testing which follows.

\subsection{Prototype Testing Using Animal Co-Design Strategies}

Both Webber [8] and French et al. [67] describe alternate animal co-design strategies, which may vary widely depending upon the species being accommodated. They emphasize the need to use flexible evaluation techniques, allowing iterative experimentation and prototype evolution. These must follow the animal's lead and, where appropriate, a visitor's lead (formative evaluation), caregiver's lead, and researcher's lead, thus homing in on the most suitable design for serving the interests of all stakeholders.

\subsection{Final Design}

Based upon staff and assumed animal approval (evaluated through testing and experienced caregiver perceptions) of the final prototype, the design team finalizes their design, confirming costs, time, and any project restrictions or additional work required by the client. Clear client approval of this stage is needed before proceeding further. 


\subsection{Final Development and Post-Occupancy Testing}

After final client approval is received, the design team will assist in providing and installing the final working ACT assembly and training staff in its use and maintenance and would later assist with maintenance and repairs for an agreed-upon period. The zoo or other client would carry out a scientific post-occupancy evaluation, considering benefits to animals, staff, and visitors.

\section{Conclusions and Further Collaborative Opportunities}

Zoos, aquariums, animal sanctuaries, and animal research facilities, like most human societies, are evolving towards greater automation to reduce human labor costs. However, rather than reducing behavioral opportunities and welfare for managed animals, creative use of ACT technology, based upon solid animal welfare science, has the potential for greatly increasing managed animal choice, control and self-sufficiency, and thus relative freedom. As we have shown, we are only at the beginning of this journey, in terms of utility, durability, and affordability. Yet on the horizon could be institution and even community-wide IT networks coordinating, safeguarding, and recording activities of semi-free-ranging animals as they manage themselves and some graduate to sustainable release and rewilding. So, as animal carers and technology designers collaborate in the creation of educational, welfare and research enhancing ACT prototypes, we are creating a widely collaborative future with the animals in our care. Adopting and advancing ACT technology in the care of wildlife can translate to potential improvements in both welfare and conservation outcomes and increases in workplace efficiency and satisfaction. This makes a strong case for ongoing collaborative development in this promising field.

Author Contributions: Conceptualization, J.C.; writing-original draft preparation, J.C. and J.H.; writing一review and editing, J.C. and J.H. Both authors have read and agreed to the published version of the manuscript.

Funding: This research received no external funding.

Conflicts of Interest: The authors declare no conflict of interest.

\section{References}

1. Gray, J. Zoo Ethics the Challenges of Compassionate Conservation; CSIRO Publishing: Clayton South, Australia, 2017.

2. Mellor, D.J.; Beausoleil, N.J. Extending the 'Five Domains' model for animal welfare assessment to incorporate positive welfare states. Anim. Welf. 2015, 24, 241-253. [CrossRef]

3. Veasey, J.S. In pursuit of peak animal welfare, the need to prioritize the meaningful over the measurable. Zoo Biol. 2017, 36, 413-425. [CrossRef] [PubMed]

4. World Association of Zoos and Aquariums (WAZA). Caring for Wildlife: The World Zoo and Aquarium Animal Welfare Strategy. Available online: https://www.waza.org/wp-content/uploads/2019/03/WAZAAnimal-Welfare-Strategy-2015_Portrait.pdf (accessed on 20 April 2020).

5. Maple, T.; Perdue, B.M. Zoo Animal Welfare; Springer: Berlin/Heidelberg, Germany, 2013.

6. Coe, J.C. Embedding environmental enrichment into zoo animal facility design. In Proceedings of the Zoo Design 2017 Conference, Wroclaw, Poland, 5-7 April 2017; pp. 20-32.

7. Mellen, J.; Sevenich Macphee, M. Philosophy of environmental enrichment: Past, present, and future. Zoo Biol. 2001, 20, 211-226. [CrossRef]

8. Webber, S.; Carter, M.; Smith, W.; Vetere, F. Co-Designing with Orangutans: Enhancing the Design of Enrichment for Animals. In Proceedings of the 2020 ACM Designing Interactive Systems Conference, Eindhoven, The Netherlands, 6-10 July 2020; pp. 1713-1725.

9. Yerkes, R.M. Almost Human; Century: New York, NY, USA, 1925.

10. Hediger, H. Wild Animals in Captivity; Dover: New York, NY, USA, 1964.

11. Markowitz, H. Behavioral Enrichment in the Zoo; Van Nostrand Reinhold: New York, NY, USA, 1982.

12. Chamove, A.S.; Anderson, J.R. Examining environmental enrichment. In Housing, Care and Psychological Well-Being of Captive and Laboratory Primates; Segal, E.F., Ed.; Noyes Data Corporation: Park Ridge, NJ, USA, 1989; pp. 183-202. 
13. Mellen, J.D.; Stevens, V.J.; Markowitz, H.A.L. Environmental enrichment for Servals, Indian elephants and Canadian otters at Washington Park Zoo, Portland. Int. Zoo Yearb. 1981, 21, 196-201. [CrossRef]

14. Shape of Enrichment Inc. Available online: https://theshapeofenrichmentinc.wildapricot.org/ (accessed on 9 November 2020).

15. Shepherdson, D.J.; Mellen, J.D.; Hutchins, M. Second Nature: Environmental Enrichment for Captive Animals; Smithsonian Institution Press: Washington, DC, USA, 1998.

16. Young, R.J. Environmental Enrichment for Captive Animals; Universities Federation for Animal Welfare, Blackwell Science: Oxford, UK, 2003. [CrossRef]

17. Coe, J. Naturalistic Enrichment. In Proceedings of the ARAZPA Conference, Perth, Australia, 26-31 March 2006.

18. Coe, J.C. Naturalizing habitats for captive primates. Zoo Biol. 1989, 8, 117-125. [CrossRef]

19. Hancocks, D. A Different Nature: The Paradoxical World of Zoos and Their Uncertain Future; University of California Press: Berkeley, CA, USA, 2001.

20. Smithsonian's National Zoo. Amazonia. Available online: https://nationalzoo.si.edu/animals/exhibits/ amazonia (accessed on 9 November 2020).

21. Bauert, M.R.; Furrer, S.C.; Zingg, R.; Steinmetz, H.W. Three years of experience running the Masoala Rainforest ecosystem at Zurich Zoo, Switzerland. Int. Zoo Yearb. 2007, 41, 203-216. [CrossRef]

22. Bronwyn, B.; Ford, J.C. Environmental Enrichment in Zoos: Melbourne Zoo's Naturalistic Approach. Thylacinus 1992, 16, 12-17.

23. Ross, S.R.; Melber, L.M.; Gillespie, K.L.; Lukas, K.E. The Impact of a Modern, Naturalistic Exhibit Design on Visitor Behavior: A Cross-Facility Comparison. Visit. Stud. 2012, 15, 3-15. [CrossRef]

24. Lindholm, J. Zoo History. In Zookeeping: An Introduction to the Science and Technology; Irwin, M.D., Stoner, J.B., Cobaugh, A.M., Eds.; University of Chicago Press: Chicago, IL, USA, 2013; pp. 31-42.

25. Sommer, R. What Do We Learn at the Zoo? Nat. Hist. 1972, 81, $26-29$.

26. Martin, C.F.; Shumaker, R.W. Computer tasks for great apes promote functional naturalism in a zoo setting. In Proceedings of the Fifth International Conference on Animal-Computer Interaction, Atlanta, GA, USA, 4-6 December 2018.

27. Matsuzawa, T. WISH cages: Constructing multiple habitats for captive chimpanzees. Primates 2020, 61, 139-148. [CrossRef]

28. Pryor, K. Karen Pryor on Behavior: Essays \& Research; Sunshine Books, Inc.: North Bend, WA, USA, 1995.

29. Laule, G.E.; Desmond, T.J. Use of positive behavioral techniques in primates for husbandry and handling. In Proceedings of the AAZV Annual Conference Proceedings, South Padre Island, TX, USA, 21-26 October 1990; pp. 269-273.

30. Coe, J.C. Activity-Based Design and Management: New Opportunities for Apes and People. In Proceedings of the Apes: Challenges for the 21st Century, Brookfield, IL, USA, 10-13 May 2000; pp. 143-145.

31. Coe, J.C. Zoo Animal Rotation: New Opportunities from Home Range to Habitat Theater. In Proceedings of the AZA Annual Conference Proceedings, Wheeling, WV, USA; 1995; pp. 77-80. Available online: https://www.academia.edu/27347849/Zoo_Animal_Rotation_New_Opportunities_from_Home_ Range_to_Habitat_Theater (accessed on 8 December 2020).

32. Lukas, K.E.; Hoff, M.P.; Maple, T.L. Gorilla behavior in response to systematic alternation between zoo enclosures. Appl. Anim. Behav. Sci. 2003, 81,367-386. [CrossRef]

33. Walczak, J. Multi-Species Rotation: A New Concept for Animal Display and Management Louisville Zoo's New Islands Exhibit. In Proceedings of the AZA Annual Conference Proceedings, Bethesda, MD, USA; 1995; pp. 543-544.

34. Coe, J.C. Next generation rotation exhibits, raceway networks and space to explore. In Proceedings of the ZAA Annual Conference Proceedings, Auckland, New Zeland, 25-28 March 2014.

35. Ragan, P.; Center for Great Apes, Wauchula, FL, USA. Personal communication, 2017.

36. Clay, A.W.; Perdue, B.M.; Gaalema, D.E.; Dolins, F.L.; Bloomsmith, M.A. The use of technology to enhance zoological parks. Zoo Biol. 2011, 30, 487-497. [CrossRef]

37. Brando, S.; Buchanan-Smith, H.M. The 24/7 approach to promoting optimal welfare for captive wild animals. Behav. Process. 2018, 156, 83-95. [CrossRef] 
38. Hirskyj-Douglas, I.; Pons, P.; Read, J.; Jaen, J. Seven Years after the Manifesto: Literature Review and Research Directions for Technologies in Animal Computer Interaction. Multimodal Technol. Interact. 2018, 2, 30. [CrossRef]

39. Edwards, M.C.; Hoy, J.M.; Fitzgibbon, S.; Murray, P.J. Bandicoot bunkers: Training wild-caught northern brown bandicoot (Isoodon macrourus) to use microchip-automated safe refuge. Aust. Mammal. 2020. [CrossRef]

40. Whitham, J.C.; Miller, L.J. Using technology to monitor and improve zoo animal welfare. Anim. Welf. 2016, 25, 395-409. [CrossRef]

41. Webber, S.; Carter, M.; Smith, W.; Vetere, F. Interactive technology and human-animal encounters at the zoo. Int. J. Hum. Comput. Stud. 2017, 98, 150-168. [CrossRef]

42. Perdue, B.M.; Clay, A.W.; Gaalema, D.E.; Maple, T.L.; Stoinski, T.S. Technology at the zoo: The influence of a touchscreen computer on orangutans and zoo visitors. Zoo Biol. 2012, 31, 27-39. [CrossRef]

43. Egelkamp, C.L.; Ross, S.R. A review of zoo-based cognitive research using touchscreen interfaces. Zoo Biol. 2019, 38, 220-235. [CrossRef]

44. Broda-Bahm, C. Think tank: Evolution and revolution. Mus. News 1997, 76, 44-48.

45. Dolins, F.L.; Schweller, K.; Milne, S. Technology advancing the study of animal cognition: Using virtual reality to present virtually simulated environments to investigate nonhuman primate spatial cognition. Curr. Zool. 2017, 63, 97-108. [CrossRef]

46. Coe, J.C. Giving Lab Animals Choices. Lab Anim. Mag. 1994, 24, 41-42.

47. Banhazi, T.M.; Black, J.L. Precision Livestock Farming: A Suite of Electronic Systems to Ensure the Application of Best Practice Management on Livestock Farms. Aust. J. Multi Discip. Eng. 2009, 7, 1-14. [CrossRef]

48. Feedpods: Automatic Feeder with App Control for Zoos, S.P.a.A. Feedpods. Available online: https: //www.feedpods.com (accessed on 9 November 2020).

49. Creighton, G.; Carrigy, K.; Dublin Zoo, Dublin, Ireland. Personal communication, 2020.

50. Dubois, A. Developing and evaluating the impact of an automatic food dispenser on Potos flavus and Vulpes zerda. RATEL J. Assoc. Br. Ir. Wild Anim. Keep. 2020, 47, 12-16.

51. Gray, M.; Meehan, J.; Ward, C.; Langdon, S.P.; Kunkler, I.H.; Murray, A.; Argyle, D. Implantable biosensors and their contribution to the future of precision medicine. Vet. J. 2018, 239, 21-29. [CrossRef]

52. Hoy, J.M.; Murray, P.J.; Tribe, A. The potential for microchip-automated technology to improve enrichment practices. Zoo Biol. 2010, 29, 586-599. [CrossRef]

53. Gibson, K.; Dallas Zoo Savanna Curator, Dallas, TX, USA. Personal communication, 2020.

54. Hoy, J.M. Microchip-Automated Husbandry as Enrichment for Captive Animals. Ph.D. Thesis, The University of Queensland, Brisbane, Australia, 2010.

55. Sure Petcare. The Story so Far. Available online: https://www.surepetcare.com/en-gb/about/the-story-so-far (accessed on 27 August 2020).

56. Muns, S.J.; Hoy, J.M.; Murray, P.J. Microchips for macropods: First use of a microchip-automated door by a bridled nailtail wallaby (Onychogalea fraenata). Zoo Biol. 2018, 37, 274-278. [CrossRef]

57. Edwards, M.C.; Hoy, J.M.; Fitzgibbon, S.; Murray, P.J. Training a wild-born marsupial to use microchip-automated devices: The brush-tailed phascogale (Phascogale tapoatafa) as proof of concept. Aust. Mammal. 2019, 41, 279-282. [CrossRef]

58. Harley, D.; Mawson, P.; Olds, L.; McFadden, M.; Hogg, C. The contribution of captive breeding in zoos to the conservation of Australia's threatened fauna. In Recovering Australian Threatened Species: A Book of Hope; Garnett, S., Woinarski, J., Lindenmayer, D., Latch, P., Eds.; CSIRO Publishing: Collingwood, Australia, 2018; pp. 281-294.

59. Edwards, M.C.; Hoy, J.M.; Fitzgibbon, S.; Murray, P.J. Monitoring with microchips: Microchip-automated doors as a potential novel method for tracking the survival of released Northern Brown Bandicoots. Ecol. Manag. Restor. 2020. [CrossRef]

60. Carter, M.; The University of Sydney, Sydney, NSW, Australia. Personal communication, 2020.

61. Webber, S.; University of Melbourne, Victoria, Australia. Personal communication, 2020.

62. Creighton, G.; Dublin Zoo, Dublin, Ireland. Personal communication, 2020.

63. Routman, E.; Korn, R. The Living World Revisited: Evaluation of high-tech exhibits at the St Louis Zoo. Museumedia 1994, 3, 3-5. 
64. Hoy, J.M.; Murray, P.J.; Tribe, A. Thirty years later: Enrichment practices for captive mammals. Zoo Biol. 2010, 29, 303-316. [CrossRef] [PubMed]

65. Hosey, G.; Melfi, V. Human-animal bonds between zoo professionals and the animals in their care. Zoo Biol. 2012, 31, 13-26. [CrossRef] [PubMed]

66. Coe, J.C. What's the Message? Exhibit Design for Education. In Proceedings of the AAZPA Regional Conference Proceedings, Wheeling, WV, USA; 1987. Available online: http://joncoedesign.com/pub/PDFs/ WhatMessage1987.pdf (accessed on 8 December 2020).

67. French, F.; Mancini, C.; Sharp, H. More than human aesthetics. In Designing Interactive Systems, Proceedings of the 2020 ACM Designing Interactive Systems Conference; ACM: New York, NY, USA, 2020; pp. 1661-1672. [CrossRef]

Publisher's Note: MDPI stays neutral with regard to jurisdictional claims in published maps and institutional affiliations.

(C) 2020 by the authors. Licensee MDPI, Basel, Switzerland. This article is an open access article distributed under the terms and conditions of the Creative Commons Attribution (CC BY) license (http://creativecommons.org/licenses/by/4.0/). 